\title{
Model Arus Permukaan Teluk Lampung pada Musim Peralihan II dengan Pendekatan Hidrodinamika
}

\author{
Ayuk Milasari $^{1 *}$, Dwi Haryo Ismunarti ${ }^{1}$, Elis Indrayanti ${ }^{1}$, Farid Muldiyatno², \\ Aris Ismanto ${ }^{1}$, Aziz Rifai ${ }^{1}$ \\ ${ }^{1}$ Departemen Oseanografi, Fakultas Perikanan dan Ilmu Kelautan, Universitas Diponegoro \\ Jl. Prof. H. Sudarto, SH, Tembalang Semarang. Jawa Tengah 50275 Indonesia \\ ${ }^{2}$ Primer Koperasi Angkatan Laut (Primkopal) Pusat Hidrografi dan Oseanografi TNI Angkatan Laut (Pushidrosal) \\ Jl. Pantai Kuta V/I Ancol Tim. No.1, Pademangan, Jakarta Utara 14430 \\ Email: ayukmilasari97@gmail.com
}

\begin{abstract}
Abstrak
Lokasi geografis Teluk Lampung yang terletak di Pulau Sumatra bagian Selatan dan dipisahkan dari Pulau Jawa melalui Selat Sunda mempunyai akses langsung dengan perairan lepas dari Samudera Hindia. Hal ini akan berpengaruh terhadap pola sirkulasi arus permukaan yang terbentuk. Penelitian ini bertujuan untuk memodelkan arus permukaan di Teluk Lampung dengan menggunakan pendekatan model hidrodinamika khususnya pada musim peralihan II (Oktober - November 2020). Verifikasi model dilakukan dengan cara membandingkan hasil model arus dengan hasil pengukuran arus lapangan menggunakan current meter valeport yang dilaksanakan dari tanggal 12 Oktober sampai 9 November 2020. Hasil penelitian menunjukkan bahwa arus permukaan dominan dibangkitkan oleh pasang surut dengan prosentase arus pasang surut sebesar $89,09 \%$. Tipe pasang surut adalah tipe campuran condong harian ganda dengan nilai Formzall 0,4. Kecepatan arus maksimum 0,168 m/s ke arah $352^{\circ}$ dan arus minimum $0,017 \mathrm{ke}$ arah $33^{\circ}$, sehingga arah pergerakan cenderung bolak balik. Pada kondisi pasang, arus bergerak ke utara yaitu dari Selat Sunda masuk ke perairan Teluk Lampung, dan sebaliknya pada saat surut arus bergerak ke arah selatan keluar dari perairan Teluk Lampung menuju Selat Sunda.
\end{abstract}

Kata kunci : Pola Arus, Pasang Surut, Teluk Lampung, Hidrodinamika 2D

\section{Abstract \\ Lampung Bay Surface Current Model in $2^{\text {nd }}$ Transitional Monsoon with Hydrodynamic Approach}

Lampung Bay's geographical location, which is in the Monsoon Wind system, causes the oceanographic conditions in these waters to be influenced by the Monsoon Wind system. In second transitional monsoon, it has the most significant current velocity value with the dominant direction due to the entry of water masses from the Indian Ocean to Lampung Bay. It has a risk to the direction of shipping. This research analyzes the pattern of sea current movement and characteristics in Lampung Bay in the 2nd Transitional Monsoon (October-November). Verification of the model's suitability is carried out by comparing the results of field measurements carried out on 12 October -9 November 2020. This research used a descriptive quantitative method. The data processing results indicate that current with a maximum speed of $0,168 \mathrm{~m} / \mathrm{s}$ in the direction of $352^{\circ}$ and a minimum speed of $0,017 \mathrm{~m} / \mathrm{s}$ to the $33^{\circ}$ with tidal current characteristics of $89,09 \%$. The tidal wave of Lampung Bay is categorized as the mixed tidal wave with an inclination to the double. The simulation models using the 2D Hydrodynamics approach suggest the direction of the current wave, which tends to go back and forth or reverse caused by tidal dominance with the average velocity of $0,03 \mathrm{~m} / \mathrm{s}$. During the high tide, the current pattern moves towards Lampung Bay to the north from Sunda Strait; meanwhile, during low tide, the current pattern moves in a counter direction towards the outside of Lampung Bay to the south heading to Sunda Strait.

Keywords : Current Pattern, Tide, Lampung Bay, 2D Hydrodynamics 


\section{PENDAHULUAN}

Teluk Lampung merupakan sarana pintu gerbang utama dalam jalur transportasi laut dalam pendistribusian logistik dari Jawa menuju Sumatera maupun sebaliknya. Hal ini ditunjukkan oleh padatnya lalu lintas kapal besar yang mengangkut bahan industri dan keperluan energi serta kapal - kapal nelayan yang beraktifitas. Menurut Widhi et al. (2013) daerah kawasan Teluk Lampung merupakan daerah industri dengan tingkat pertumbuhan yang cukup tinggi sehingga dibutuhkan pengembangan akan area pelabuhan. Oleh karena itu, dalam rangka memenuhi kebutuhan pelayanan jasa kepelabuhanan, maka pemerintah setempat memiliki rencana pembangunan dan pengembangan pelabuhan guna menunjang aktifitas di sekitar teluk tersebut (ANTARA, 2019). Rencana pengembangan dan pembangunan pelabuhan memerlukan banyak informasi hidrooseanografi yang salah satunya adalah arus laut. Menurut Muhazzir et al. (2012) arus laut memiliki arti penting dalam menentukan arah pelayaran bagi kapal-kapal yang akan masuk ke pelabuhan sebagai langkah awal monitoring kondisi perairan dalam menghasilkan informasi hidrografi.

Teluk Lampung yang relatif dangkal dan posisinya yang berhadapan langsung dengan Selat Sunda dan Samudera Hindia menjadikan teluk ini memiliki karakteristik arus permukaan yang unik. Penelitian tentang arus di Teluk Lampung telah banyak dilakukan diantaranya oleh Oktavia et al. (2011) yang menyatakan bahwa pada musim peralihan II, masukkan massa air dari Samudera Hindia menuju Teluk Lampung melalui Selat Sunda menghasilkan nilai kecepatan arus yang paling besar dengan arah yang dominan. Penelitian lainnya oleh Budiwicaksono et al. (2013), Sianturi et al. (2013) dan Widhi et al. (2013) yang menyatakan bahwa arus permukaan di Teluk Lampung dipengaruhi oleh pasang surut dan sistem angin muson.

Penelitian ini dilakukan pada musim peralihan II (Oktober - November 2020) dengan tujuan untuk memodelkan arus permukaan di Teluk Lampung, mengingat besarnya dampak yang ditimbulkan dalam menentukan pengaruhnya terhadap gerak kapal yang masuk ke pelabuhan akibat proses pengembangan pelabuhan yang sedang berlangsung di sekitar Teluk Lampung. Salah satu alternatif untuk mengkaji pola arus laut adalah dengan menggunakan pemodelan hidrodinamika sehingga dapat mempermudah dalam menganalisis suatu kondisi perairan dan lebih efisien dari segi waktu, biaya dan tenaga. Hasil penelitian diharapkan dapat memberikan gambaran pola arus laut di Teluk Lampung dan mampu mewakili kondisi yang sebenarnya di lapangan agar dapat digunakan untuk keperluan pelayaran dan pengembangan pelabuhan di kawasan Teluk Lampung.

\section{MATERI DAN METODE}

Materi penelitian terdiri atas data primer yaitu data pengukuran arah dan kecepatan arus, serta data pasang surut selama 29 hari, sedangkan data sekunder berupa data batimetri, data garis pantai serta data angin selama 1 bulan yaitu dari tanggal 12 Oktober sampai 9 November 2020 dari BMKG Lampung.

\section{Pengukuran dan Pengolahan Data Arus}

Pengukuran arus dilakukan menggunakan metode eularian yakni pengamatan arus pada suatu posisi tertentu di suatu kolom air sehingga data yang di dapat adalah data arus dalam suatu titik tertentu dalam fungsi waktu. Pengukuran arus dilakukan menggunakan Current Meter Valeport $C M$ - 106 (Hardianto dan Wibowo, 2019) yang diletakkan pada satu titik tetap pada kedalaman \pm 3 meter pada koordinat $05^{\circ} 29^{\prime} 01.162^{\prime \prime}$ LS dan $105^{\circ} 18^{\prime} 56.432 "$ BT tersaji pada Gambar 1. Hasil pengolahan data arus disajikan dalam bentuk current rose. Selanjutnya dilakukan pemisahan arus pasut dan arus non pasut dari arus total untuk masing-masing komponen u dan v. Pemisahan ini dilakukan untuk mengetahui besarnya dominasi arus pasut terhadap arus total.

\section{Pengukuran dan Pengolahan Data Pasang Surut}

Pengukuran pasang surut dengan cara merekam tinggi muka air dengan interval 5 menit secara kontinyu menggunakan instrument Tide Master Pressure Digital. Pengukuran dilakukan selama 29 hari yaitu dari tanggal - November 2020 pada lokasi yang sama dengan pengukuran arus (Gambar 1).

Data pasang surut diolah menggunakan metode Admiralty yang menghasilkan komponen harmonik pasang surut yang meliputi amplitudo (A), $\mathrm{S}_{0}, \mathrm{M}_{2}, \mathrm{~S}_{2}, \mathrm{~N}_{2}, \mathrm{~K}_{1}, \mathrm{O}_{1}, \mathrm{M}_{4}, \mathrm{MS}_{4}, \mathrm{~K}_{2}$, dan $\mathrm{P}_{1}$. Setelah hasil akhir diperoleh untuk setiap 
komponen pasang surut, maka ditentukan MSL, HWL, LWL, dan bilangan Formzahl untuk mengetahui tipe pasang surut.

\section{Pengukuran Batimetri dan Garis Pantai}

Pengukuran data batimetri dilakukan dengan menggunakan metode akustik yakni mengukur jarak dengan memanfaatkan gelombang akustik ke dasar laut, kemudian dipantulkan oleh dasar laut dan diterima kembali oleh echosounder. Berdasarkan waktu tempuh gelombang dari tranducer - dasar laut transducer dan cepat rambat gelombang akustik dalam medium air laut akan dapat diketahui kedalaman perairan yang diukur (Budiwicaksono et al., 2013).
Pengukuran garis pantai dilakukan dengan mengambil titik sampel pada hasil pengolahan awal berupa analasis citra satelit (Nugraha et al., 2017). Ground check atau survei lapangan dilakukan untuk pencocokan hasil pemisahan batas darat dan batas laut yang telah dilakukan pengolahan awal yang menghasilkan informasi garis pantai.

Data yang didapat diolah untuk menghasilkan lembar lukis lapangan berupa file TIFF dan disimpan dalam bentuk ekstensi .xyz dengan isi data berupa data koordinat bujur dan lintang dalam satuan Decimal Degrees serta data kedalaman dalam satuan meter.

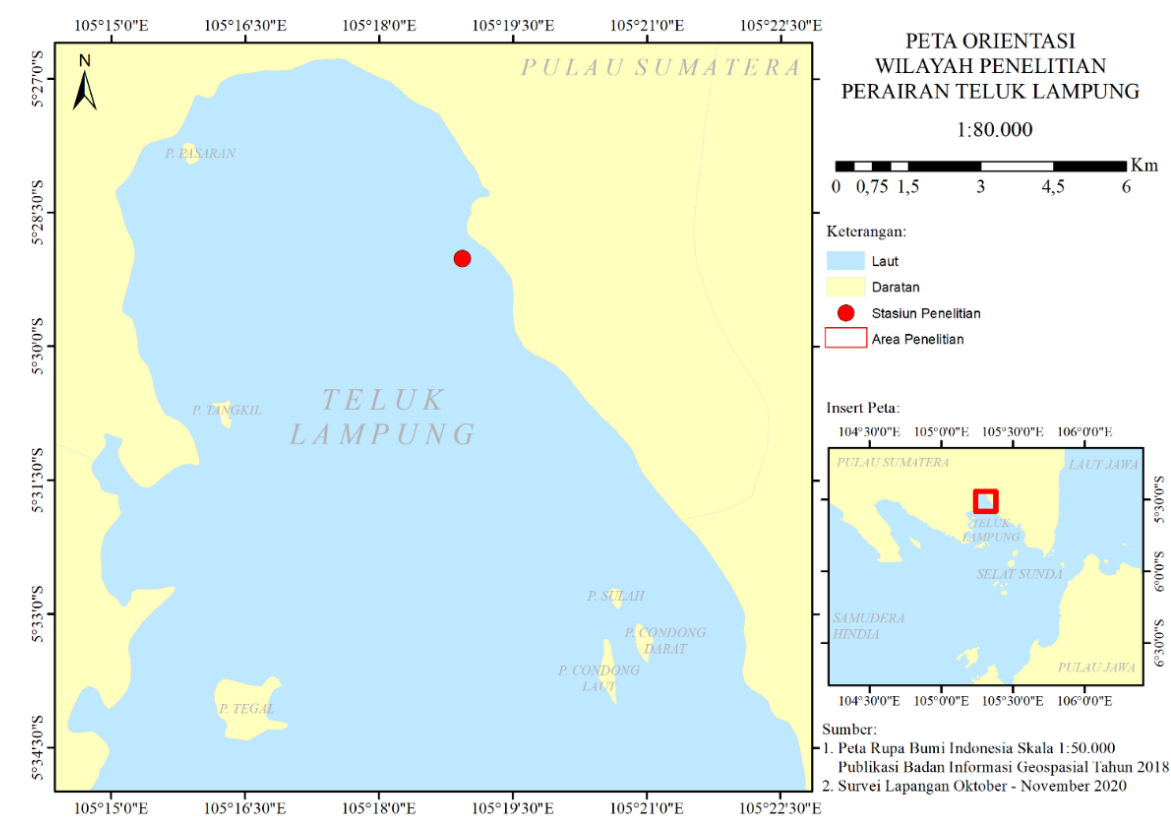

Gambar 1. Lokasi dan Titik Pengukuran Arus

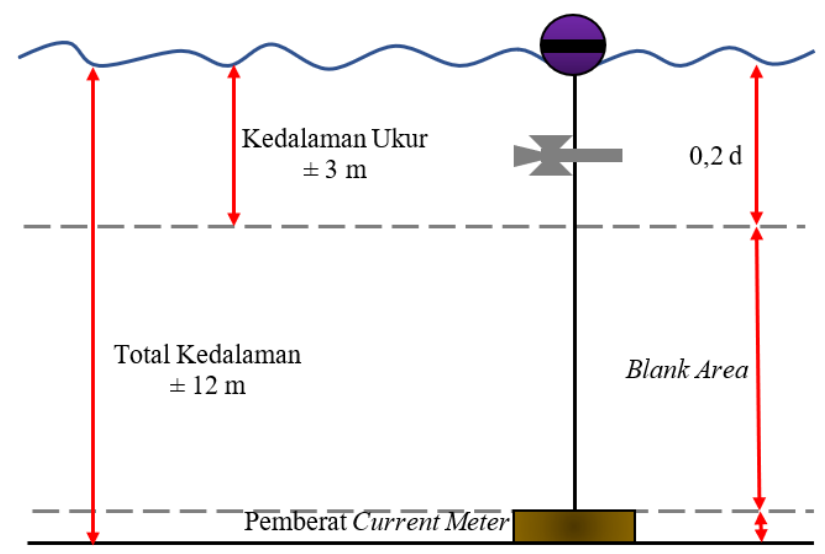

Gambar 2. Skema Pengukuran dengan Current Meter 


\section{Data Angin}

Data angin diolah berdasarkan musim yang diteliti (12 Oktober - 09 November 2020) sehingga memperoleh hasil pada satu titik koordinat dalam bentuk Text (.txt) yang disajikan dalam bentuk windrose untuk memperoleh kondisi dominan angin.

\section{Pemodelan Hidrodinamika}

Model hidrodinamika merupakan sistem model numerik umum untuk pemodelan permukaan air dan arus. Model hidrodinamika yang dikembangkan untuk mensimulasikan aliran 2D dalam satu layer fluida yang dianggap homogen secara vertikal. Amirullah et al. (2014) menambahkan terdapat dua persamaan pembangun yang mendukung model antara lain:

\section{Persamaan Kontinuitas}

$$
\frac{\partial \zeta}{\partial t}+\frac{\partial p}{\partial x}+\frac{\partial q}{\partial y}=0
$$

2. Persamaan Momentum

Pada sumbu X:

$\frac{\partial p}{\partial t}+\frac{\partial}{\partial x}\left(\frac{p^{2}}{h}\right)+\frac{\partial}{\partial y}\left(\frac{p q}{h}\right)+g h \frac{\partial \zeta}{\partial x}+\frac{\partial p \sqrt{p^{2}+q^{2}}}{c^{2} h^{2}}-\frac{1}{\rho w}\left[\frac{\partial}{\partial x}\left(h \tau_{x x}\right)+\frac{\partial}{\partial y}\left(h \tau_{x y}\right)\right]-\Omega_{q}-f V V_{x}$

Pada sumbu Y:

$\frac{\partial q}{\partial t}+\frac{\partial}{\partial y}\left(\frac{q^{2}}{h}\right)+\frac{\partial}{\partial x}\left(\frac{p q}{h}\right)+g h \frac{\partial \zeta}{\partial y}+\frac{\partial p \sqrt{p^{2}+q^{2}}}{c^{2} h^{2}}-\frac{1}{\rho w}\left[\frac{\partial}{\partial y}\left(h \tau_{y y}\right)+\frac{\partial}{\partial x}\left(h \tau_{x y}\right)\right]-\Omega_{q}-f V V_{y}$ di mana $h$ dan $d$ pada penyelesaianya mengindikasikan nilai dari kedalaman rata-rata sedangkan $u$ dan $v$ adalah kecepatan pada kedalaman rata-rata. Persamaan kontinuitas memasukan debit air dan persamaan momentum akan memasukan parameter angin dan.pasang surut dalam model hidrodinamika. (Ismanto et al., 2019). Model yang dijalankan dalam penelitian ini melalui beberapa tahapan, yaitu: Pre-processing model, persiapan data garis pantai, data batimetri, serta pembangunan unstructured triangular mesh. Processing model, set up nilai koefisien parameter model. Post-processing model, ekstraksi data hasil simulasi model numerik dan verifikasi data.

\section{Verifikasi Model}

Verifikasi digunakan untuk mengetahui tingkat kesalahan suatu simulasi model yang sudah dibuat. Verifikasi pada penelitian ini menggunakan RMSE (Root Mean Square Error) dan MAE (Mean Absolute Error) yang bertujuan untuk menunjukkan kecocokan dua jenis data (Ismunarti et al., 2020). RMSE dan MAE menggambarkan seberapa tersebarnya selisih nilai peramalan dan pengukuran dengan membandingkan antara kecapatan arus hasil simulasi model dengan kecepatan arus hasil pengukuran lapangan. RMSE dihitung berdasarkan persamaan:

$$
\text { RMSE }=\sqrt{\frac{\sum\left(x_{1 i}-x_{2 i}\right)^{2}}{n}}
$$

MAE adalah rata-rata absolut perbedaan antara kedua variabel, perbedaan ada ketika rata-rata nilai kedua variabel berbeda (Willmott and Matsuura, 2005). MAE dihitung dengan persamaan:

$$
M A E=\frac{\sum\left|x_{1 i}-x_{2 i}\right|}{n}
$$

Sebagai penunjang untuk mengukur (kuat, lemah, atau tidak ada) hubungan antar variabel (pengukuran dan peramalan) maka dilakukan perhitungan koefisien korelasi (R) dengan persamaan:

$$
r=\frac{\sum\left(x_{1 i}-\overline{x_{1 \imath}}\right)\left(x_{2 i}-\overline{x_{2 l}}\right)}{\sqrt{\sum\left(x_{1 i}-\overline{x_{1 l}}\right)^{2}} \sqrt{\sum\left(x_{2 i}-\overline{x_{2 l}}\right)^{2}}}
$$

dengan $\mathrm{n}, \mathrm{x}_{1 \mathrm{i}}$, dan $\mathrm{x}_{2 \mathrm{i}}$ berturut-turut adalah jumlah data, data lapangan, dan data hasil model.

\section{HASIL DAN PEMBAHASAN}

\section{Kecepatan dan Arah Arus}

Wulandari et al. (2021) menyatakan arus adalah energi eksternal yang mengangkut beberapa bahan tersuspensi seperti partikel mikroplastik yang memiliki nilai konsentrasi yang bervariasi. Proses ini kemudian menjadi gaya adveksi untuk beberapa konsentrasi polutan nonkonservatif. Berdasarkan hasil pengukuran diperoleh kecepatan arus minimum sebesar 0,017 $\mathrm{m} / \mathrm{s}$ ke arah $33^{\circ}$, dan kecepatan arus maksimum sebesar $0,168 \mathrm{~m} / \mathrm{s} \mathrm{ke}$ arah $352^{\circ}$, serta kecepatan rata-rata sebesar $0,0472 \mathrm{~m} / \mathrm{s}$. Kecepatan arus rata-rata sejalan dengan penelitian sebelumnya oleh Budiwicaksono et al. (2013) yaitu $0,044 \mathrm{~m} / \mathrm{s}$ pada lokasi dan musim yang sama. Gambar 3 menunjukkan current rose dimana pergerakan arus cenderung bolak - balik. Terlihat arus permukaan bergerak ke berbagai arah, namun memiliki kecenderungan di dominasi dari arah barat laut dan Tenggara.

Apabila kita amati lebih jauh pola ini juga mirip dengan pola angin yang ditunjukkan oleh wind rose pada Gambar 4 yaitu angin dominan bergerak ke arah barat laut-utara pada kecepatan rata-rata sebesar $3,58 \mathrm{~m} / \mathrm{s}$. Hal itu diduga karena 
kondisi angin yang terjadi di stasiun pengamatan juga dipengaruhi oleh sistem angin muson, yaitu angin muson barat laut yang bertiup dari barat laut menuju tenggara, dan angin muson tenggara yang bertiup dari tenggara menuju barat laut (Oktavia et al., 2011). Kecepatan arus permukaan juga dipengaruhi oleh angin permukaan dimana seiring bertambahnya kedalaman, pengaruh angin sebagai pembangkit arus akan berkurang (Wisha et al., 2015; Saputra et al., 2017).

\section{Pemisahan Arus Pasut dan Arus Non-Pasut}

Hasil pemisahan arus menunjukkan arus yang mendominasi adalah arus pasang surut dengan nilai perhitungan persentase astronomic, sebesar $89,09 \%$ dan residual sebesar 10,91\%. Hal ini juga ditunjukkan dengan data pengukuran (observed) yang berhimpitan dengan data arus pasut (astronomic) seperti tersaji pada Gambar 5. Sianturi et al. (2013) juga menyatakan bahwa arus yang terjadi di Teluk Lampung yang sebagian besar perairannya berupa perairan dangkal memiliki karakteristik arus dengan kecepatan yang tidak begitu besar dan didominasi oleh arus pasang surut.

Hasil perhitungan pasang surut diperoleh nilai bilangan Formzahl sebesar 0,46 sehingga dapat diketahui tipe pasang surut di Teluk Lampung adalah tipe pasang surut campuran condong ke harian ganda dimana dalam satu hari terjadi dua kali pasang dan dua kali surut dengan amplitudo dan waktu yang berbeda. Hal ini juga diperkuat oleh beberapa penelitian sebelumnya pada daerah yang sama, seperti Sianturi et al. (2013) dan Budiwicaksono et al. (2013) dengan tipe pasang surut campuran condong ke harian ganda dan hasil perhitungan pasang surut nilai bilangan Formzahl yang tidak jauh berbeda sebesar 0,47. Sedangkan untuk kedudukan air laut dengan nilai MSL adalah $429 \mathrm{~cm}$, HWL adalah $509 \mathrm{~cm}$ dan LWL adalah $340 \mathrm{~cm}$ (Tabel 1).

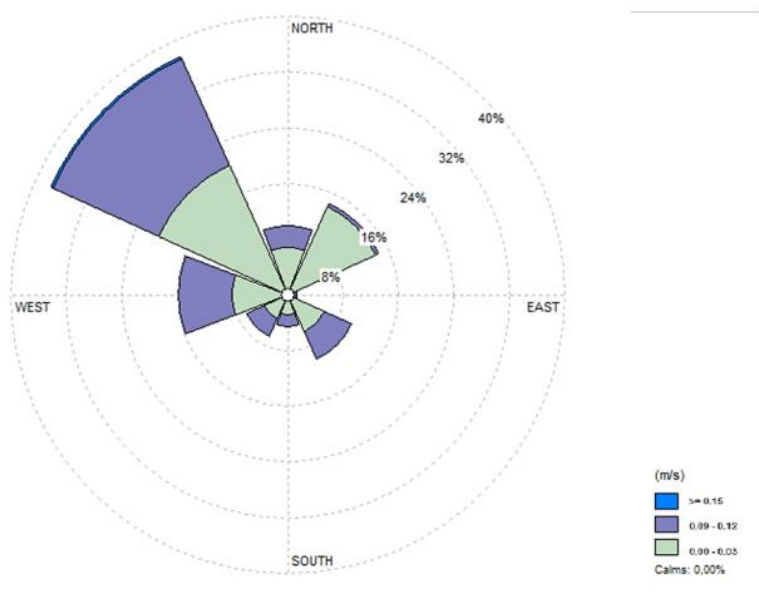

Gambar 3. Current Rose Teluk Lampung

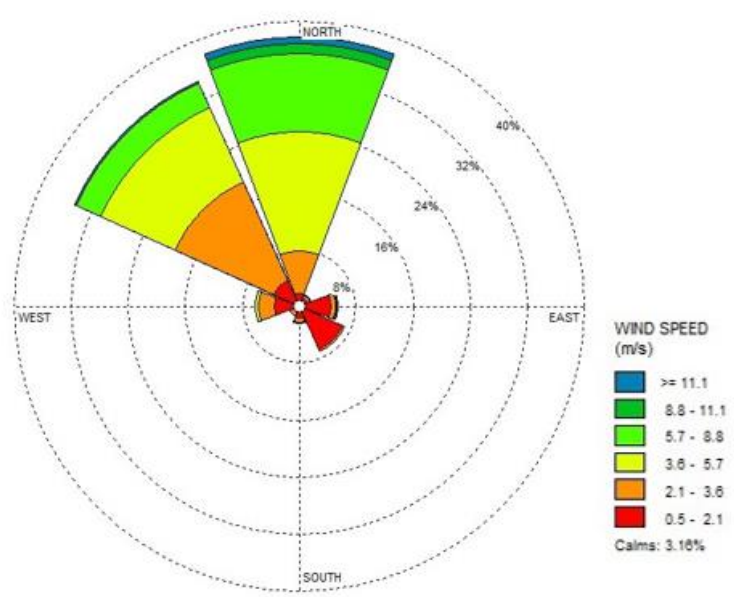

Gambar 4. Wind Rose Teluk Lampung 
Tabel 1. Data Kedudukan Air Laut

\begin{tabular}{cc}
\hline Kedudukan Air Laut & Amplitudo $(\mathrm{cm})$ \\
\hline MSL & 429 \\
HWL & 509 \\
LWL & 340 \\
\hline
\end{tabular}

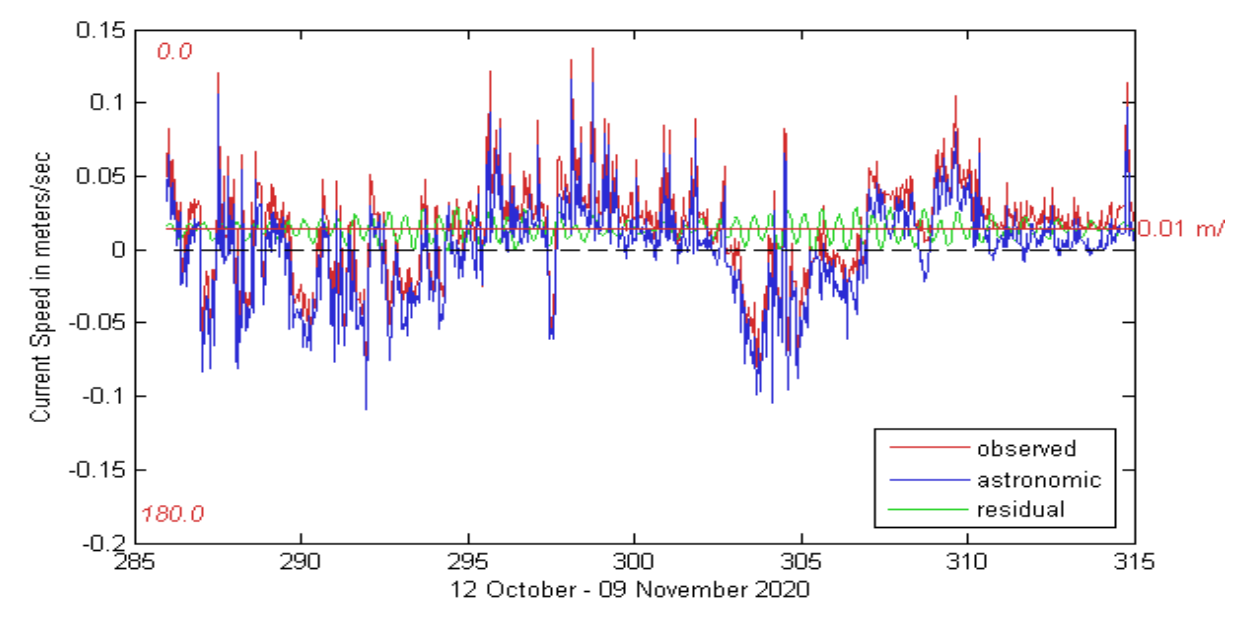

Gambar 5. Grafik Karakteristik Arus Permukaan

\section{Model Arus Teluk Lampung}

Pada kondisi arus saat pasang tertinggi (Gambar 6A), pola arus bergerak ke arah utara melewati pulau-pulau bagian dalam teluk dengan kecepatan arus berkisar 0,062 - 0,093 m/s kemudian masuk ke dalam mulut teluk bergerak mengikuti garis pantai ke arah Barat Laut dengan kecepatan berkisar $0,031-0,062 \mathrm{~m} / \mathrm{s}$. Semakin masuk menjauh ke dalam mulut teluk, kecepatan arus semakin berkurang dengan kisaran kecepatan di bawah $0,031 \mathrm{~m} / \mathrm{s}$. Kondisi pasang menuju surut dengan kecepatan rata-rata sebesar $0,02 \mathrm{~m} / \mathrm{s}$, pola arus di sekitar pesisir bagian barat teluk bergerak menuju Selatan kemudian berbelok ke arah Barat Daya sehingga terjadi perputaran arus bolak-balik (Gambar 6B). Pada kondisi surut terendah, pola arus bergerak ke arah Selatan keluar teluk, dimana kecepatan pada ujung utara teluk memiliki kisaran kecepatan $0,027 \mathrm{~m} / \mathrm{s}$ semakin menuju ke arah Selatan teluk, kecepatan semakin besar dengan nilai kecepatan berkisar $0,50-0,105 \mathrm{~m} / \mathrm{s}$ (Gambar 6C). Sementara saat kondisi surut menuju pasang (Gambar 6D), di pulau-pulau bagian tengah, pola arus yang berasal dari pesisir berbelok ke Barat Laut lalu ke Utara ketika melewati Pulau Pasaran dan Pulau Tangkil dengan kisaran kecepatan $0,033-0,066 \mathrm{~m} / \mathrm{s}$, pada daerah Pulau Tegal pola arus bergerak ke arah Utara sedangkan pola arus yang melewati Pulau Sulah, Pulau Condong Darat, dan Pulau Condong Laut berbelok ke Timur Laut menuju ke Utara dan Barat Laut dengan kecepatan arus rata-rata sebesar 0,027 $\mathrm{m} / \mathrm{s}$. pada bagian tengah teluk juga terlihat kecepatan arus berkisar $0,066 \mathrm{~m} / \mathrm{s}$ menuju ke arah Timur Laut dan dibelokkan ke arah Barat Laut mengikuti topografi teluk.

Nilai elevasi muka air mencapai 5,03-5,08 meter pada saat kondisi pasang tertinggi (Gambar 7A) sedangkan elevasi di utara teluk berkisar lebih dari 5,08 meter. Pada kondisi pasang menuju surut, nilai elevasi muka air yang terjadi berkisar 4,45 meter dan terus mengalami penurunan elevasi hingga 4,44 meter (Gambar 7B). Pada kondisi surut terendah, nilai elevasi muka air mengalami penurunan menjadi 3,72 - 3,79 meter dikarenakan pergerakan massa air yang keluar dari teluk akibat surut nya air laut (Gambar 7C). Sementara pada saat kondisi surut menuju pasang, nilai elevasi muka air yang relatif mirip dengan kondisi saat pasang menuju surut yakni berkisar 4,45 meter (Gambar 7D).

Berdasarkan hasil model ditunjukkan bahwa arah arus di Teluk Lampung cenderung mengikuti garis pantai dan tidak ada pembelokan yang besar, kecuali pada daerah pesisir yang mana terjadi perputaran arus. Hal ini bisa saja 

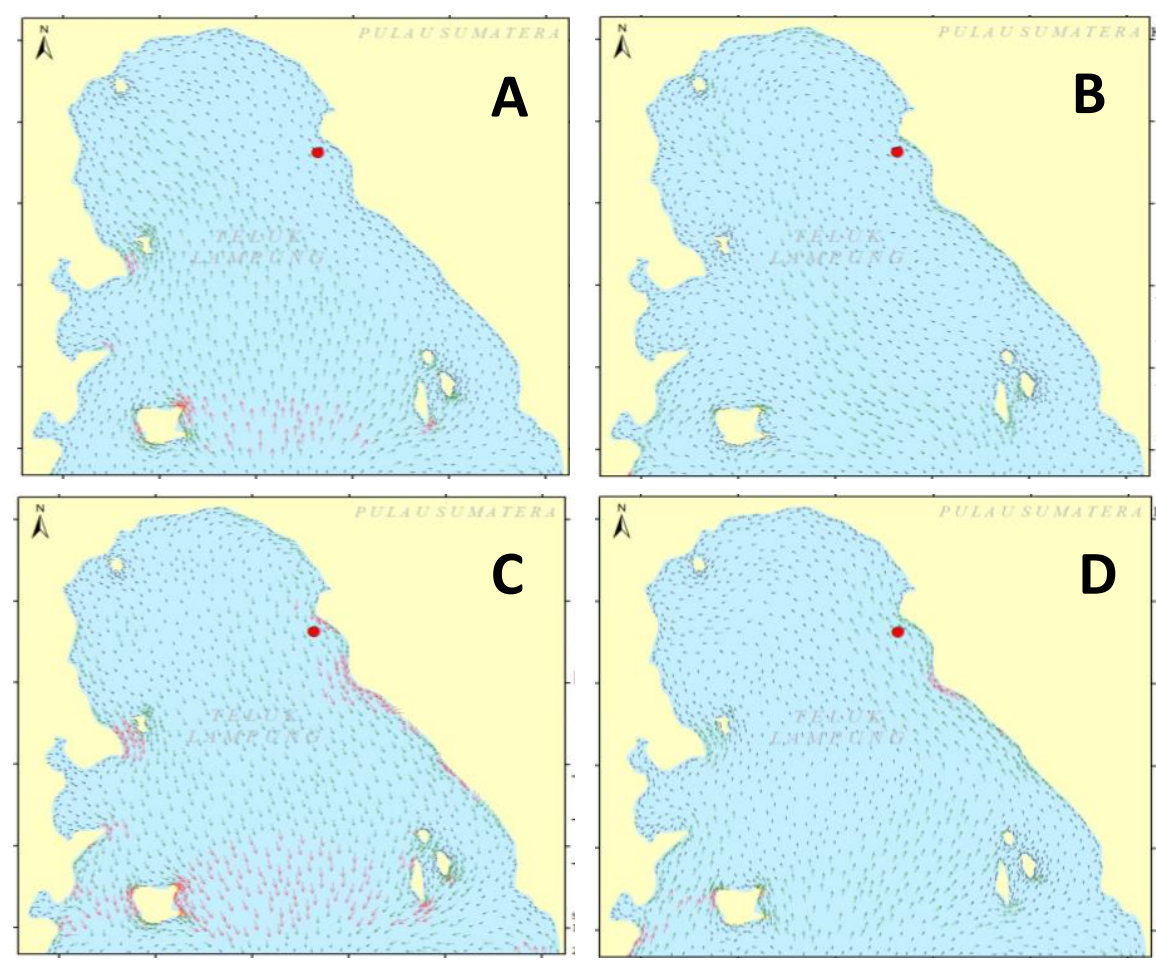

Gambar 6. Pola Arus pada saat (A) Saat Pasang Tertinggi, (B) Pasang Menuju Surut, (C) Surut Terendah dan (D) Surut Menuju Pasang
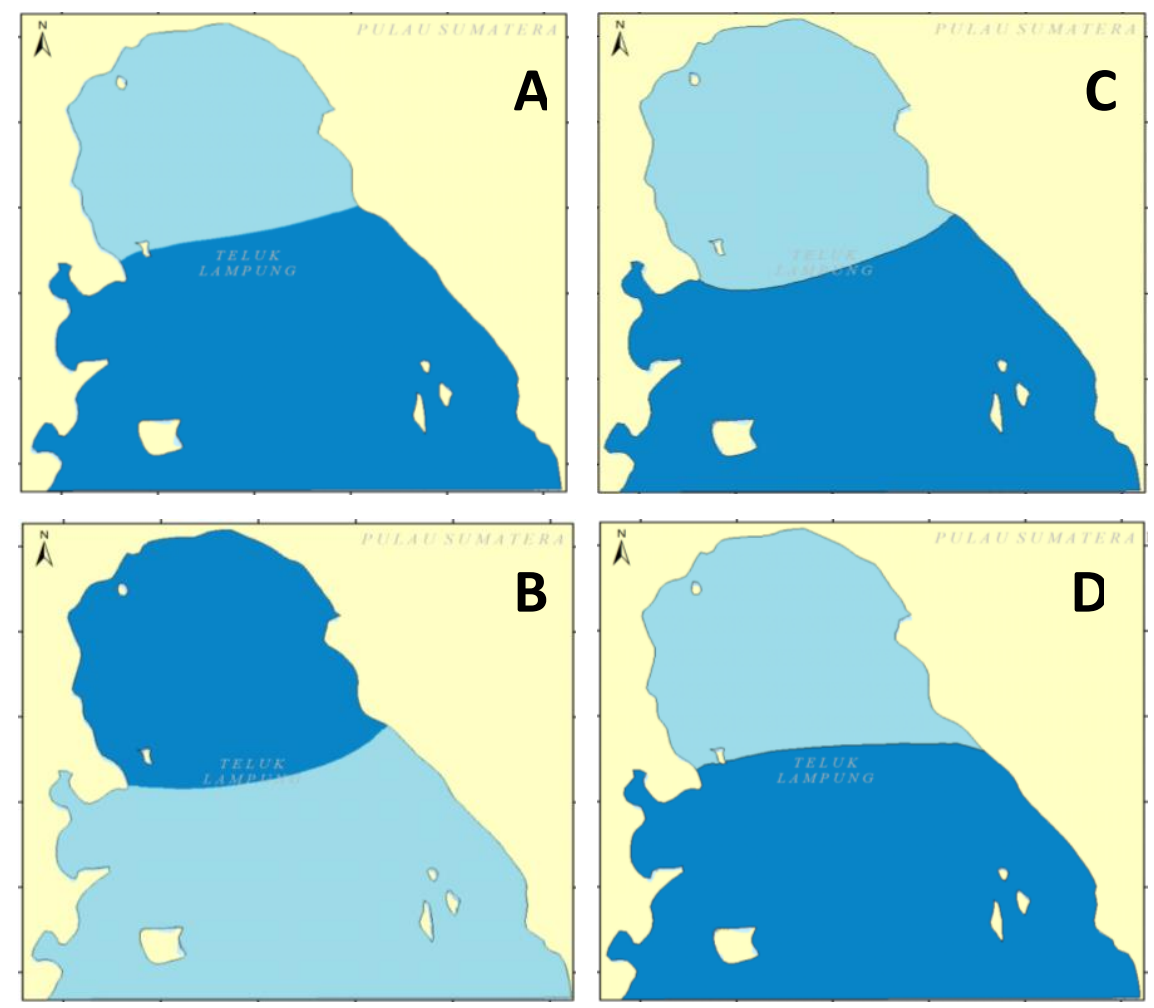

Gambar 7. Elevasi Muka Air pada saat (A) Saat Pasang Tertinggi, (B) Pasang Menuju Surut, (C) Surut Terendah dan (D) Surut Menuju Pasang 
disebabkan oleh arus yang menjalar terhalang oleh bangunan sehingga terjadi pembelokkan arah arus. Adanya pengembangan pelabuhan yang berupa pengerukan yang terletak di kawasan Pelabuhan Panjang sekitar stasiun penelitian juga hanya memiliki pengaruh sangat kecil dalam perubahan kecepatan arus laut dan pergerakan arus lautnya. Hal itu ditunjukkan dengan kecepatan arus rata-rata yakni $0,04 \mathrm{~m} / \mathrm{s}$ untuk arus model dan $0,0472 \mathrm{~m} / \mathrm{s}$ arus lapangan dengan dominasi arusnya sama-sama ke arah Barat Laut pada saat terjadinya pengembangan pelabuhan yang tidak jauh berbeda dengan penelitian Budiwicaksono et al. (2013) berdasarkan lokasi dan musim penelitian yang sama sebelum pengembangan pelabuhan dengan kecepatan arus rata-rata sebesar $0,044 \mathrm{~m} / \mathrm{s}$ ke arah Barat Laut.

Kondisi saat pasang tertinggi dan surut terendah model memiliki kecepatan arus rata-rata lebih besar dibandingkan dengan kondisi lainya. Arus maksimum juga terlihat di kawasan berupa celah sempit yang menghubungkan pesisir Lampung dengan pulau-pulau di dalamnya. Kondisi ini mengakibatkan terkonsentrasinya arus laut akibat terhambat oleh bentuk topografi yang berupa celah sempit tersebut sehingga menyebabkan sirkulasi massa air di perairan ini memiliki kecepatan arus yang lebih tinggi dibandingkan pada lokasi lain (Syahputra et al., 2014). Oleh karena itu, pada area teluk kecepatan arus mengalami fluktuasi akibat adanya perbedaan batimetri.
Pola pergerakan arus hasil model di Teluk Lampung juga menunjukkan tipe reversing current (bolak-balik), dimana pada saat pasang arus bergerak masuk, dan pada saat surut arus bergerak ke arah luar teluk (Muhazzir et al., 2012). Pernyataan ini juga diperkuat oleh Widhi et al. (2013), dimana massa air di Teluk Lampung secara nyata dipengaruhi oleh pasang surut, dimana massa air ini berpindah secara vertikal mengikuti air pasang memasuki Teluk Lampung dari Utara dan bersamaan air surut meninggalkan teluk dari arah Selatan menuju Selat Sunda.

\section{Verifikasi Hasil Model}

Pada perhitungan RMSE dan MAE antara hasil kecepatan arus model dengan arus lapangan didapatkan nilai sebesar 0,0334 dan 0,0227 (Gambar 8), sedangkan nilai error elevasi pasang surut model dengan elevasi pasang surut lapangan sebesar 0,015 dan 0,0126 (Gambar 9). Menurut Moriasi et al. (2007), perhitungan RMSE dan MAE memiliki klasifikasi seperti Sangat Baik jika bernilai $0-0,5$; Baik jika bernilai $0,5-0,6$; Cukup jika bernilai 0,6 - 0,7 dan Tidak baik jika bernilai > 0,7. Dengan kata lain, apabila kesalahan (error) model semakin kecil maka model bisa dikatakan baik. Sedangkan, perhitungan koefisien korelasi kedua data menghasilkan nilai koefisien korelasi (r) sebesar 0,9215 untuk elevasi muka air dan 0,9463 untuk kecepatan arus. Hal ini menunjukkan bahwa kedua variabel berkorelasi positif dan memiliki keeratan hubungan sangat tinggi (Ismunarti et al., 2020).

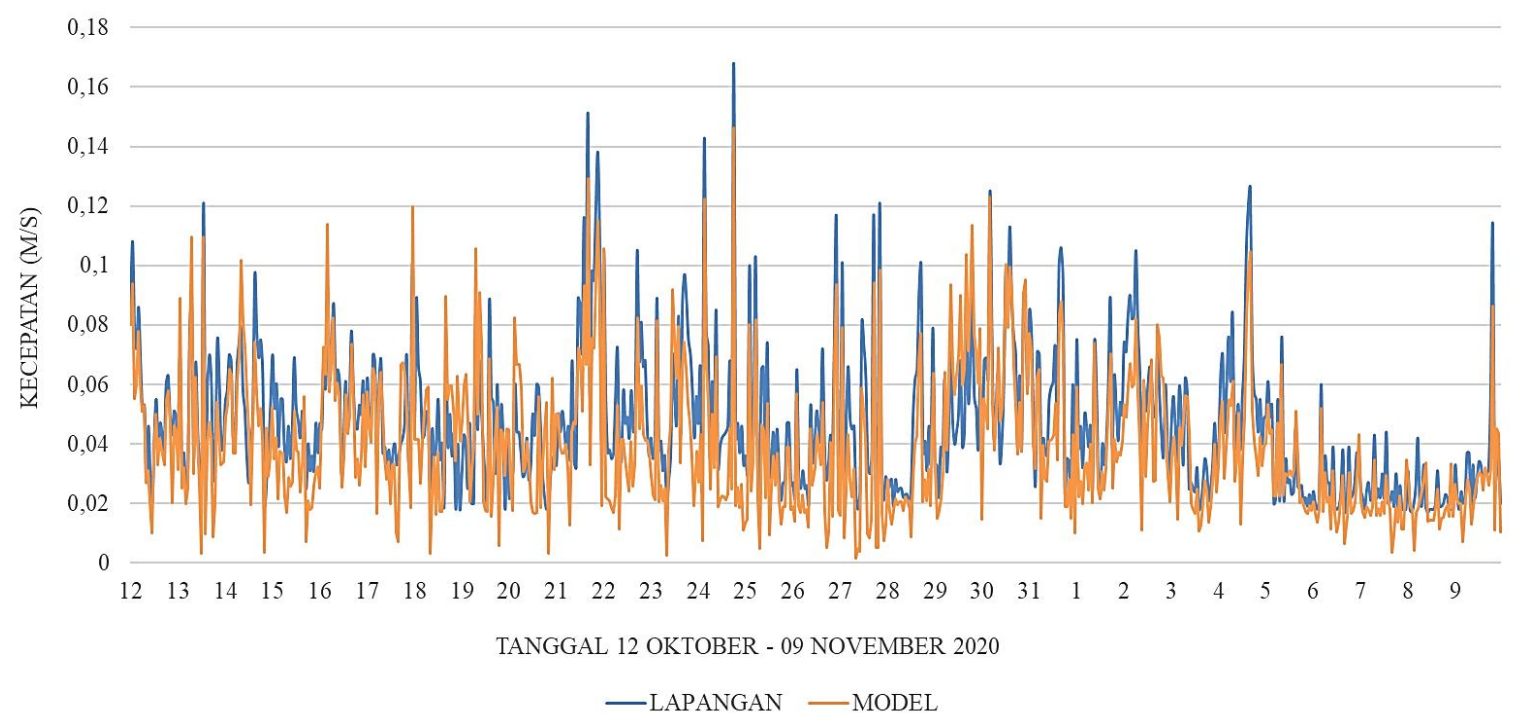

Gambar 8. Grafik Verifikasi Kecepatan Arus 


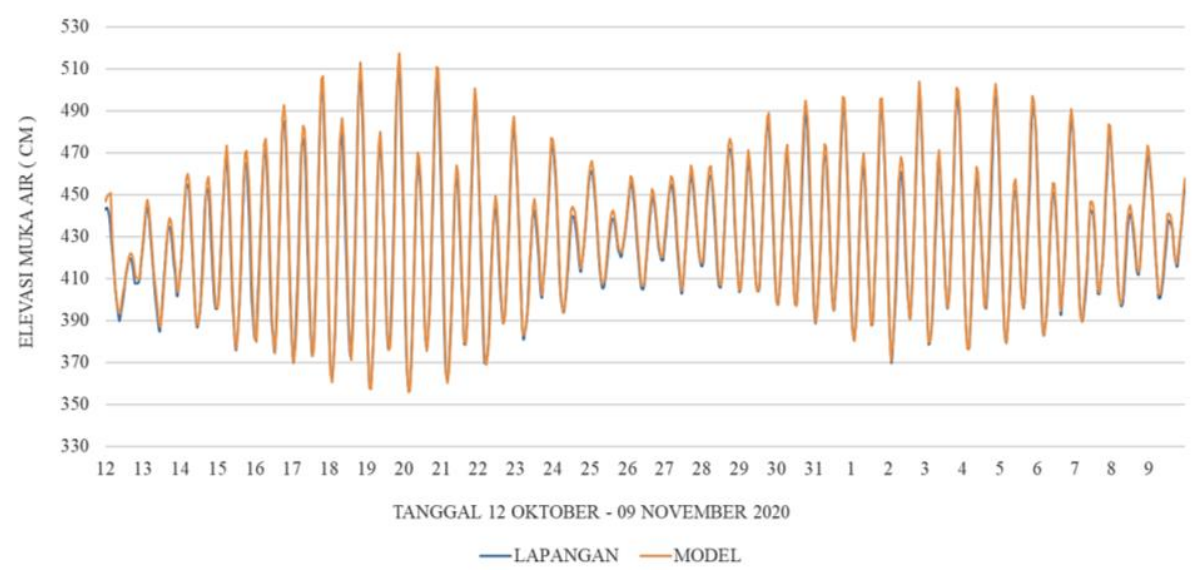

Gambar 9. Grafik Verifikasi Elevasi Pasang Surut

\section{KESIMPULAN}

Arus laut di Teluk Lampung memiliki kecepatan rata-rata sebesar $0,0472 \mathrm{~m} / \mathrm{s}$. Arus dipengaruhi pasang surut sebesar 89,09\% dan juga dipengaruhi oleh angin. Pola pergerakan arus mengikuti pola pergerakan pasang surut dengan tipe pasang surut campuran condong ke ganda. Pada kondisi pasang, pola arus bergerak dari Selat Sunda ke arah Utara dan memasuki Teluk Lampung ke arah Barat Laut dengan nilai elevasi muka air rata-rata sebesar 5,06 meter sedangkan saat surut pola arus berbalik arah keluar Teluk Lampung ke arah Selatan menuju Selat Sunda dengan nilai elevasi muka air rata-rata sebesar 3,76 meter.

\section{UCAPAN TERIMA KASIH}

Penulis menyampaikan terimakasih kepada Primer Koperasi Angkatan Laut (Primkopal) Pusat Hidrografi dan Oseanografi TNI Angkatan Laut (Pushidrosal) atas diizinkanya penulis bergabung dalam kegiatan Survei "Alur Pelayaran dan Penetapannya pada Pelabuhan Panjang di Teluk Lampung".

\section{DAFTAR PUSTAKA}

Amirullah, A.N., Sugianto, D.N. \& Indrayanti, E. 2014. Kajian Pola Arus Laut Dengan Pendekatan Model Hidrodinamika Dua Dimensi Untuk Pengembangan Pelabuhan Kota Tegal. Jurnal Oseanografi, 3(4):671682.
ANTARA. 2019. Pelabuhan Panjang Lampung Jadi Pelabuhan Internasional. antaranews.com. Diakses pada tanggal 7 April 2021 pukul 13.43 WIB.

Budiwicaksono, A.R., Subardjo, P. \& Novico, F. 2013. Pemodelan Pola Arus Pada Tiga Kondisi Musim Berbeda Sebagai Jalur Pelayaran Perairan Teluk Lampung Menggunakan Software Delft3d. Journal of Oceanography, 2(3):280-292.

Ismanto, A., Ismunarti, D.H., Sugianto, D.N., Maisyarah, S., Subardjo, P., Suryoputro, A.D.S., \& Siagian, H. 2019. The Potential of Ocean Current as Electrical Power Sources Alternatives in Karimunjawa Islands Indonesia. Advances in Science, Technology and Engineering Systems Journal. 4(6):126133.

Ismunarti, D.H., Zainuri, M., Sugianto, D.N. \& Saputra, S.W. 2020. Pengujian Reliabilitas Instrumen Terhadap Variabel Kontinu Untuk Pengukuran Konsentrasi Klorofil-a Perairan. Buletin Oseanografi Marina, 9(1):1-8.

Moriasi, D.N., Arnold, J.G., Van Liew, M.W., Bingner, R.L., Harmel, R.D. \& Veith, T.L., 2007. Model Evaluation Guidelines for Systematic Quantification of Accuracy in Watershed Simulations. Journal American Society of Argicultural and Biological Enginners, 50(3):885-900.

Muhazzir, M., Widada, S., \& Ismunarti, D.H. 2012. Kajian Pola Arus Laut Sebelum Dan Sesudah Pembangunan Pelabuhan Khusus Pabrikasi Baja Di Perairan Paciran, Kabupaten Lamongan. Journal of Oceanography, 1(1): 69-77. 
Nugraha, I.N.J., Karang, I.W.G.A. \& Dharma, I.G.B.S. 2017. Studi Laju Perubahan Garis Pantai di Pesisir Tenggara Bali Menggunakan Citra Satelit Landsat (Studi Kasus Kabupaten Gianyar dan Klungkung). Journal of Marine and Aquatic Science, 3(2): 204-214.

Oktavia, R., Pariwono, J.I., \& Manurung, P. 2011. Variasi Muka Laut dan Arus Geostrofik Permukaan Perairan Selat Sunda Berdasarkan Data Pasut dan Angin Tahun 2008. Jurnal Ilmu dan Teknologi Kelautan Tropis, 3(2): 127-152.

Saputra, V.H., Rifai, A., \& Kunarso, K. 2017. Variabilitas Musiman Pola Arus di Perairan Surabaya Jawa Timur. Journal of Oceanography, 6(3):439-448.

Sianturi, O.R., Widada, S., Prasetyawan, I.B., \& Novico, F. 2013. Pemodelan Hidrodinamika Sederhana Berdasarkan Data HidroOseanografi Lapangan di Teluk Lampung. Journal of Oceanography, 2(3):299-309.

Syahputra, H., Prasetyawan, I.B., Ismunarti, D. H., \& Adhitya, R.B. 2014. Kajian Potensi
Arus Laut Sebagai Energi Pembangkit Listrik Di Selat Larantuka, Flores Timur, Nusa Tenggara Timur. Buletin Oseanografi Marina, 3(1):1-8.

Widhi, K.B., Indrayanti, E., \& Prasetyawan, I.B. 2013. Kajian Pola Arus Di Perairan Teluk Lampung Menggunakan Pendekatan Model Hidrodinamika 2-dimensi Delft3d. Journal of Oceanography, 1(2):169-177.

Willmott, C.J. \& Matsuura, K. 2005. Advantages of The Mean Absolute Error (MAE) Over The Root Mean Square Error (RMSE) In Assessing Average Model Performance. Climate Research, 30:79-82.

Wisha, U.J., Husrin, S. \& Prihantono, J. 2015. Hidrodinamika Perairan Teluk Banten Pada Musim Peralihan (Agustus - September). Journal of Marine Sciences, 20(2):101-112.

Wulandari, S.Y., Radjasa, O.K., Yulianto, B., Ismanto, A., Muslim, Marwoto, J., Siagian, H. \& Maisyarah, S. 2021. Microplastics model distribution in Semarang Waters. Research Journal of Chemistry and Environment, 25(1):109-120. 